\title{
Central Trial Meeting Material
}

National Cancer Institute

\section{Source}

National Cancer Institute. Central Trial Meeting Material. NCI Thesaurus. Code C115597.

A collection of agendas, presentation materials, and other documents generated for attendees during a central trial-related meeting. 